\title{
EL RETRATO DEL PERIODISTA EN LA OBRA DE JOSÉ JOAQUÍN FERNÁNDEZ DE LIZARDI
}

The Image of the Journalist in the work by José Joaquín Fernández de Lizardi

Mariela Insúa*

Resumen

Este artículo ofrece una aproximación a la imagen del periodista en el México de finales de la colonia y comienzos de la vida independiente, a través de la obra del mexicano José Joaquín Fernández de Lizardi (1776-1827). Se exponen en la argumentación las referencias meta-periodísticas presentes en sus principales obras de prensa - El Pensador Mexicano, Conversaciones del Payo y el Sacristán, Alacena de friolera- y también en sus Folletos. El trabajo se estructura a partir de tres ejes temáticos: el periodismo y la libertad, el periodismo como oficio y la crítica a los periodistas poco éticos o "chabacanos".

Palabras clave: Fernández de Lizardi, México (1810-1827), periodismo, imagen del periodista

\section{Abstract}

This article offers an approach to the image of the journalist in the transition between colonial and independent periods in Mexico, through the journalistic work of José Joaquín Fernández de Lizardi (1776-1827). In the argument we reviewed the metajournalistic references in his main newspapers —El Pensador Mexicano, Conversaciones del Payo y el Sacristán, Alacena de friolera - and also in his Folletos. The essay is structured on three principal topics: journalism and freedom, the journalism as a profession, and the criticism of unethical journalists called by Lizardi "chabacanos".

Key words: Fernández de Lizardi, México (1810-1827), Journalism, Image of the Journalist.

Las referencias a la actividad del escritor periódico constituyen uno de los ejes centrales - junto con el debate acerca de asuntos civiles, sociales y eclesiásticos y las cuestiones referentes a América y a la educación- de la obra de prensa del mexicano José Joaquín Fernández de Lizardi. ${ }^{1}$ Recordemos a este respecto que durante el siglo ilustrado el periodista se transforma en el nuevo hombre de letras, en un nuevo tipo de escritor que se aleja del modelo del sabio humanista que genera saberes alejado del mundanal ruido. La prensa periódica pasa a constituir un naciente tipo de literatura que se brinda al servicio del público, que quiere ser "útil", pero que también considera a la masa lectora como su nuevo mecenas. En este contexto, la reflexión acerca de la propia labor responde al interés del periodista por consolidarse como sujeto recién arribado a la República literaria.

\footnotetext{
${ }^{1}$ Para un exhaustivo estudio de la obra periodística de De Lizardi, ver Oviedo y Pérez de Tudela (1982) y para una síntesis del papel del periodista como agente social (Insúa, 2010).
} 


\section{Mariela Insúa}

Fernández de Lizardi, ya en la misma elección del título de su principal periódico, El Pensador Mexicano, pone de manifiesto cuál ha de ser su función como agente informador y crítico. La posterior adopción de ese título como seudónimo pone aún más en evidencia que el mexicano se considera por sobre todo un "pensador". Un pensador-periodista del estilo de otro que también fue llamado como su periódico: José Clavijo y Fajardo. De este modo, los artículos de Lizardi se muestran en la misma línea del Pensador español, quien era a su vez continuador del estilo del The Tatler y del The Spectator. Por ello Lizardi puede ser valorado como un eslabón americano en la cadena de un modo de escritura periodística caracterizada por la observación atenta de la sociedad, cuyo fin central era poder aportar útilmente a su funcionamiento. Aportación que debía hacerse, desde la mirada ilustrada, a partir del ideal de una comunicación clara, es decir, que unívocamente pudiera transmitir lo racional y lo verdadero (Franco, 1983:4-5).

Por otro lado, el estilo llano y apasionado de Lizardi demuestra la íntima unión que para él existe entre el pensar y el escribir. En efecto, en sus artículos se puede vislumbrar a un escritor que no corrige, porque trabaja a contrarreloj; pero también porque "escribe a la vez que piensa" (Oviedo y Pérez de Tudela, 1982:534). Sin embargo, esta espontaneidad pasa por el tamiz del respeto a sus iguales y del temor a la censura. Por ello, muchas veces, según él mismo confiesa, se expresa a través de un decir "enmascarado"

Lo gracioso es que después de tantas signadas y santiguadas, me suelo quedar con la pluma en la mano, la izquierda bajo la barba y los ojos en las vigas del techo como extático, porque se me representan en el magín algunas picardías e iniquidades de los hombres que, al paso que quisiera descubrirlas con la mayor energía para que los tales que se viesen de cuerpo entero en este espejo, o se enmendasen o se hiciesen más abominables al público, al mismo tiempo, digo, me veo precisado a dorar o a disfrazar estas mismas iniquidades poniéndoles la máscara menos fea que puedo: esto lo hago unas veces por caridad, otras por política y otras por no contraerme enemistades tal vez con aquellos a quienes no ha sido mi intención hablar determinantemente, sino que su malicia perversa sabe corromper la expresión más sencilla (Obras III:52-53).

Tal como expresa Jean Franco, Fernández de Lizardi se erige como modelo del nuevo hombre de letras, que es "pensador" no por hacer alarde de una sabiduría abstracta, sino por procurar únicamente mediar entre el saber y la sociedad (1983:12). Es decir, que propone comunicar y divulgar las ideas modernas a una población que estaba ávida por recibirlas. Tampoco pretende el autor mexicano mostrarse como original, ni sus lectores esperaban de él tal originalidad. Como muchos ilustrados de la época, Lizardi, el autodidacta, inserta en sus trabajos ideas extraídas de misceláneas y compendios (de ahí que, 


\section{El retrato del periodista en la obra de José Joaquín Fernández de Lizardi}

en algunas ocasiones, cometa errores de atribución). ${ }^{2}$ Sus enemigos y detractores criticaron en varias ocasiones la costumbre lizardiana de hilvanar las ideas propias con las ajenas, y lo acusaron de plagio. Acusaciones que molestaron sobremanera al periodista y contra las que respondió enfáticamente en varios de sus folletos. Así lo hace, por ejemplo, en "Otra afeitada de El Pensador al miserable Barbero" (1822)

Sépase, el mi señor, que plagio es el robo literario, que se hace apropiándose alguno un discurso ajeno; pero el trabajar un discurso propio sobre lo que ha estudiado en los autores, no es plagio. En tal caso, todos los sermones serían plagios y todas las defensas de los abogados, porque se fundan los unos en los Evangelios, Escrituras, santos padres expositores, etcétera; y las otras en las leyes, historias, comentadores, glosadores y autores que tratan la materia. Pregunte usted a su abogado y verá qué buen disparate ha dicho, cuando para probar que mi Sueño es copia, me cita a Neker, Aguesau, Caracciolo y más de cuatro docenas de publicistas que usted no conoce por el forro (Obras XII:159).

\section{PERIODISMO Y LIBERTAD}

Para Fernández de Lizardi, la comunicación del pensamiento ha de estar vinculada a la libertad. Una de las principales luchas que abanderó el mexicano con su pluma fue la de poder escribir libremente. Por ello explicaba a sus lectores, en el número inaugural de El Pensador Mexicano, que existe un modo de esclavizar que consiste en poner trabas a la expresión

Así el hombre que piensa, siempre que se halla imposibilitado de comunicar sus pensamientos al público por medio de la prensa, es un mudo intelectual, y mientras más vivamente piense, mientras sea más penetrativo, tanto más ha de sentir el yugo insoportable de esta cadena (Obras III:34).

La libertad de imprenta constituye un tema recurrente en los escritos periodísticos de Lizardi y, en general, su escritura se encuentra sujeta a los avatares de la libertad de imprenta en esta época tan convulsa. Así, escribe sin tapujos en los períodos en los que ésta es decretada y procura, en cambio, ceñirse a los criterios censores, dirigiendo su crítica a aspectos sociales o educativos, o inventando modos subrepticios de expresión, en las etapas de suspensión de la misma. Sin embargo, sus lidias contra el organismo censor y luego con la Inquisición ${ }^{3}$ serán permanentes,

\footnotetext{
${ }^{2}$ Así sucede, por ejemplo, en un folleto de 1822, titulado "Desvergüenzas y excomuniones no destruyen las sólidas razones", en el que atribuye al padre Isla la famosa "Sátira contra los malos escritores de este siglo" de Jorge Pitillas (publicada en el Diario de los literatos en 1742), pues seguramente la leyó del Rebusco de las obras literarias del jesuita, en la que fue incluida por error. Ver Fernández de Lizardi, Obras XII:149, № 3.

${ }^{3}$ El 30 de diciembre de 1814, con el regreso de Fernando VII al trono, se reinstaura la Inquisición.
} 


\section{Mariela Insúa}

y varias veces sus periódicos verán peligrar su publicación. ${ }^{4}$ Este "tambaleo" en el estilo periodístico del mexicano deja de existir en la última etapa de su producción (1820-1827) — que coincide con el período independiente que le toca vivir-, en la que se muestra más definido en la exposición de sus ideas políticas y mucho más certero a la hora de criticar. ${ }^{5}$

De entre el conjunto de reflexiones del Pensador acerca de la libertad de imprenta destacan aquellas insertas en uno de sus periódicos más famosos, las Conversaciones del Payo y el Sacristán. En 1825, en el número 11 de esta publicación, expone rotundamente que en la libertad de imprenta "se hallan refundidas todas las libertades" y que, por lo tanto, "el menor amago que se le hace a la libertad de imprenta es un golpe mortal que se le da a toda la libertad social". Por esto mismo, en palabras del periodista, "cualquiera enemigo de la libertad de imprenta debe verse como sospechoso de la nación, así como sus defensores se deben considerar como verdaderos patriotas liberales" (Obras $V: 377)$. Cabe señalar que, para Lizardi, esta tan añorada libertad de escritura requiere, para ser tal, sus límites. De este modo se subraya en el artículo 90 de la "Constitución política de una república imaginaria", que se inserta en las Conversaciones del Payo y el Sacristán. Aquí se defiende que "todos los hombres son libres para expresar sus pensamientos por las prensas, lo mismo que con la palabra" (486); pero para que no se abuse de esta libertad, "con perjuicio del orden público", son imprescindibles ciertas restricciones como: no atacar con mala intención a la forma de gobierno establecida, ni al dogma religioso; no ir en contra de la moral del pueblo con impresos obscenos; no publicar las faltas privadas de los ciudadanos (sí las públicas). El sacristán —alter ego del Pensador- propone duras reprimendas contra aquellos que no respeten estas necesarias restricciones: expatriación para los autores de papeles subversivos, multas para los que publiquen papeles escandalosos y juicio para los que escriban injurias. Como podemos apreciar, en estas declaraciones, Fernández de Lizardi se muestra como el patriota que brega por la instauración de la libertad en todas las áreas de expresión; pero que se comporta también como el ideólogo ilustrado que defiende la máxima del orden y el respeto mutuo (es decir, la norma del bien común) que necesariamente ha de reinar en una sociedad racional, para que ésta se desenvuelva armónicamente.

\footnotetext{
${ }^{4}$ El Pensador Mexicano, que apareció al poco tiempo de decretarse la libertad de imprenta en México (5 de octubre de 1812), será censurado en diciembre de ese mismo año debido a que en el $\mathrm{N}^{\circ}$ 9, Lizardi increpaba al virrey Venegas para que revocara un edicto en el que autorizaba el juicio militar de unos curas revolucionarios. A partir de este momento los problemas de Lizardi con la Junta de Censura serán permanentes. El tema de la libertad de imprenta en los artículos periodísticos de Lizardi ha sido abordado en detalle por Oviedo y Pérez de Tudela (1982:509-515).

${ }^{5}$ Este cambio de estilo motivado por las circunstancias políticas ha sido enfatizado por Chencinsky en el estudio preliminar a la edición de El Pensador Mexicano (Obras III:16-26).
} 


\section{El retrato del periodista en la obra de José Joaquín Fernández de Lizardi}

Mas, sin duda, es en los folletos de Lizardi donde el tema de la libertad de imprenta adquiere mayor relevancia. Por ejemplo, en 1821, en un papel titulado "Defensa de la libertad", el Pensador reitera, apoyándose en lo promulgado por las Cortes de Cádiz, que la soberanía de la nación ha de estar sostenida por la libertad de imprenta y que, por ello, atacar a una es atacar a la otra (Obras XI:356). Esta misma idea constituye la base de su exposición en el "Proyecto sobre libertad de imprenta", del mismo año que el citado folleto. En este proyecto subraya además la utilidad que brinda la libertad de imprenta a la hora de "desterrar abusos, sofocar preocupaciones, ilustrar al pueblo y contener en sus deberes a los administradores de las leyes" (Obras XI:331). Porque, al fin y al cabo, tal como señala el mexicano en otro folleto también de 1821, "uno de los objetos más sagrados a que debe destinarse la libertad de la imprenta es a ilustrar al Gobierno, haciéndole conocer la opinión pública, proponiéndole los medios eficaces para la conservación del buen orden y felicidad de la nación" (Obras XI:351).

Una perspectiva crítica acerca del desarrollo que está teniendo la libertad de imprenta en México es aportada por Lizardi en un folleto de 1822 titulado "Maldita sea la libertad de imprenta. Diálogo entre don Liberato y don Servilio". Aquí vemos, a través de la conversación entre un defensor de la escritura en libertad (don Liberato) y un recalcitrante que opina que la libertad de imprenta ha sido nefasta para la nación (don Servilio), las trabas que seguían existiendo a la hora de expresarse, aun cuando se podía publicar libremente. Porque, tal como explica don Liberato, se dejaba publicar todo aquello que los autores daban a las prensas, pero luego, una vez aparecidas las publicaciones, se les ponían mil trabas

Imprime el escritor lo que quiere, es verdad, sin previa censura; mas no sin censura posterior. Sale su papel, y se queda temiendo si no le gustará al señor fiscal, si lo denunciará, si le tocarán buenos jueces en primer juri, o si irá a la cárcel a hacer la cuenta de la impresión. Ésta no me atreveré a llamarla libertad de imprenta, sino peligro de imprenta (Obras XI:511).

En fin, el tema de la libertad de imprenta es abordado satíricamente en verso en el poema "De don Servilio al clamor sea sordo el emperador", donde el personaje - en una tertulia de serviles - le aconseja a Iturbide que declare la guerra contra todo aquel que tenga pensamientos propios, con el fin de que todos se conviertan en jumentos (Obras XII:5).

\section{EL "OFICIO" DE PERIODISTA}

Otra cuestión diferente que hay que destacar dentro de las reflexiones metaperiodísticas en los artículos de Lizardi, se relaciona con el aspecto económico de la actividad de los nuevos hombres de letras. Recordemos que el quehacer del periodista en la Ilustración se encuentra marcado, entre otras cuestiones, por la 


\section{Mariela Insúa}

transformación del producto de la escritura en un bien de cambio. ${ }^{6}$ El Pensador es consciente de que necesita al público lector desde el punto de vista pecuniario. Requiere, pues, que se compren sus escritos para poder seguir publicando y también para subsistir, y él confiesa sin tapujos que vive gracias a su escritura. Por esto mismo no duda en dedicar El Periquillo Sarniento - en un prólogo dialogado de resonancias cervantinas - a los lectores que comprarán los fascículos, porque a fin de cuentas ellos serán los verdaderos "mecenas" que costearán la impresión. Así conmina graciosamente a que adquieran las sucesivas entregas de su obra

Dignaos, pues, acogerla favorablemente, comprando cada uno seis o siete capítulos cada día, y subscribiéndoos por cinco o seis ejemplares, a lo menos, aunque después os deis a Barrabás por haber empleado vuestro dinero en una cosa friona y fastidiosa; aunque me critiquéis de arriba abajo, y aunque hagáis cartuchos o servilletas con los libros; que como costeéis la impresión con algunos polvos de añadidura, jamás me arrepentiré de haber seguido el consejo de mi amigo; antes, desde ahora para entonces, y desde entonces para ahora, os escojo y elijo para únicos mecenas y protectores de cuantos mamarrachos escribiere, llenándoos de alabanzas como ahora y pidiendo a Dios que os guarde muchos años, os dé dinero y os permita emplearlo en beneficio de los autores, impresores, papeleros, comerciantes, encuadernadores y demás dependientes de vuestro gusto (1997:95).

Los periódicos de Lizardi también suelen comenzar con una dedicatoria a los lectores. De este modo, en el primer número de El Pensador Mexicano el periodista brinda su obra a los potenciales "consumidores" de su publicación

A usted dedico mi tal cual trabajo, porque ¿a quién sino al lector se le dedican los libros? Si le gustare, podrá comprar este papel y los que le sigan; si no, tan amigos como siempre (Obras III:34).

Más adelante, en el primer número del segundo tomo de este mismo periódico, identifica a su lector ideal con los hombres de bien, aquellos "legítimos conocedores del mérito" (Obras III:149). Por otro lado, a pesar de la necesidad de compradores para poder seguir publicando, el Pensador prefiere que aquellos que no tengan abierta la mente a recibir opiniones diferentes, eviten adquirir sus papeles. De esta manera lo expresa con el tono punzante que le es tan propio

El primer número del tomo tercero saldrá el jueves venidero, pues hasta ahora hay muy pocos subscriptores. Los que sean muy tontos de la cabeza, muy envenenados de corazón o estén reñidos con la verdad y la justicia (sean de esta o aquella especie), pueden omitir el subscribirse,

\footnotetext{
${ }^{6}$ Para más detalles de esta cuestión en el periodismo español $-\mathrm{y}$ aplicable, también, al ámbito hispanoamericano - ver Álvarez Barrientos "El periodista en la España del siglo XVIII y la profesionalización del escritor" (1990); y "Cuando las letras llegaron a ser "de cambio": sobre la República literaria española en el siglo XVIII” (1993), recogidos en la bibliografía final.
} 


\section{El retrato del periodista en la obra de José Joaquín Fernández de Lizardi}

comprar o leer mis papeles, pues yo no quiero causar a nadie disgustos ni cóleras, que no están los tiempos para eso (Obras III:374).

Fernández de Lizardi hizo de la escritura periódica un oficio y contestó duramente a aquellos que lo criticaron por vivir de su pluma. No dudó en defenderse de los que lo acusaron por concebir el periodismo como un trabajo cualquiera, sujeto a los avatares de la economía. Para el escritor mexicano las letras son un bien de cambio y es justo que, si se incrementa el valor de la materia prima (el papel), suba el precio del producto final. Así lo manifiesta en el prospecto del segundo tomo de El Pensador Mexicano, al plantear que él se queja de la subida del costo de la vida tal como lo hace cualquier comerciante, y que es un trabajador más al servicio del público y que, por tanto, ha de comer del público

Si se le arguye a cualquier comerciante con la carestía de sus géneros, inmediatamente alega: que las guerras, que los insurgentes, que los costos, fletes, alcabalas, averías, comisiones, etcétera, etcétera. ¿Por qué, pues, no le ha de ser lícito al escritor cuando encarece sus obras alegar que el papel está sobre diez y ocho o veinte pesos resma, que sale a medio real el pliego blanco, que los costos de la imprenta son subidos, que a los repartidores se les paga su trabajo y a los expendedores también, etcétera, etcétera, etcétera? Muy bien está que el fin primario de todo escritor no ha de ser únicamente el lucro; pero tampoco es justo que se pierda el tiempo y el dinero [...]. Nadie nota que se pague al orador su sermón, al abogado su alegato, ni al médico su curación; ¿Por qué se ha de llevar a mal que al autor se le pague su trabajo? (Obras III:155).

En varios folletos, Lizardi responde a quienes critican que escriba pane lucrando. Así le contesta, por ejemplo, a un personaje apodado el Ciudadano, quien lo había atacado por confesar que hacía negocio con la escritura

Lo que he dicho e impreso es que "cuando escribo trato de conciliar mi interés particular con la utilidad común", y esto ¿qué tiene de nuevo ni de malo? Ni uno he visto yo que trabaje de balde para el público, aunque a éste le resulte beneficio de su trabajo.

El labrador, el artesano, el comerciante, el letrado, el sacerdote, el médico... en una palabra, todos los que sirven al público; ¿pues por qué no ha de gozar iguales ventajas el escritor que impende más difíciles tareas en beneficio de sus semejantes? (Obras X:301).

También se muestra rotundo cuando le contesta al Papista, quien se había burlado de él diciendo que se estaba muriendo de hambre y que por eso necesitaba de su pluma para sobrevivir

El escribir para comer nada tiene de particular, lo malo fuera que escribiera para beber. El artesano trabaja, como el labrador, para comer; el comerciante y el militar lo mismo; el abogado y el médico defienden y curan a los hombres para comer; el canónigo se da tan mala vida para 
comer; el cura y su vicario administran los sacramentos para comer; y usted, para comer, se metió a fraile. Conque, ¿qué extraño se le hace que el escritor trabaje para comer cuando no hay quien no trabaje para lo mismo? (Obras XI:540). ${ }^{7}$

Como señala Jean Franco, este afán de Lizardi por equiparar el oficio de la escritura a los otros oficios es apreciable incluso en los títulos de algunas de sus publicaciones periódicas (1983:3-4); es el caso de Alacena de Frioleras (1815-1816) y de su suplemento, Cajoncitos de la Alacena (1815-1816). Esta cualidad del escritor como "vendedor de letras" puede apreciarse claramente en el artículo "La gran barata de frioleras", en el que el periodista se muestra ofertando friolerillas en palabras, así como otros hacen barata de géneros (Obras IV:99). Sin embargo, no debemos olvidar que estos títulos se relacionan con otros preexistentes en la Península - recordemos que Lizardi era un ávido lector de la prensa española-, entre los que destaca especialmente el Cajón de sastre (1760-1761), de Francisco Mariano Nifo. Tales denominaciones hacían alusión a la cualidad de miscelánea de estas publicaciones en las que podía entrar de todo; de hecho, la Alacena y los Cajoncitos son los periódicos más variopintos del autor mexicano, desde el punto de vista temático, y también en lo que se refiere a las distintas modalidades genéricas empleadas.

\section{LOS PERIODISTAS "CHABACANOS"}

Otro aspecto destacable en la configuración del modelo de periodista que Lizardi propone en sus escritos de prensa se realiza por contraposición; es decir, a través de la crítica al quehacer periodístico equivocado. De este modo, nos encontramos con abundantes pasajes en los que el mexicano se lanza contra sus pares que escriben sin ton ni son, movidos por la mera palabrería o carentes de escrúpulos a la hora de referirse a sus semejantes. Así, en el primer número de los Cajoncitos de la Alacena, se declara en "guerra eterna" contra "los periodistas chabacanos de México", tachándolos de "copistas miserables, zurcidores tiñosos, que os andáis arañando sobre quién es más penco y para nada, sobre quién se quita el pan de la boca, y sobre quién tiene más arte para sacar el medio o el real al pobre público con sus copias y boberías" (Obras IV:175). A continuación se dirige al Diarista (posiblemente Jacobo de Villaurrutia, fundador del Diario de México) y al Noticiero (identificado con el editor del Noticioso general). Al primero le critica la falta de originalidad de sus artículos, pues se limita

\footnotetext{
${ }^{7}$ Tachar a Lizardi de interesado a la hora de escribir fue una de las primeras críticas que se lanzaron contra él. Ya en 1811, el árcade Juan María Lacunza (bajo el seudónimo de Batilo) reprobaba que Lizardi se jactara de vivir de la escritura y que pretendiera agradar al "aguador, la cocinera, el muchacho". Referido por Chencinsky en su Introducción a Fernández de Lizardi, Obras I:32-38.
} 


\section{El retrato del periodista en la obra de José Joaquín Fernández de Lizardi}

únicamente a transcribir retazos del Espíritu de los diarios, una publicación famosa en la época que extractaba noticias de la prensa europea. En este mismo sentido opina del Noticiero, al que califica de "copiador bisoño", pues lo único que sabe hacer son rejuntes de noticias viejas e inútiles (Obras IV:176).

Mediante estas críticas, el Pensador indirectamente pone de manifiesto cuál ha de ser la práctica de un periodismo que aporte algo a la sociedad. De esta manera, poco importará que los escritores públicos informen acerca de datos superfluos como "quién fue el jefe del día en la plaza o quién dio guardia en el hospital", sino que beneficiará más al pueblo que el escritor periódico se convierta en un defensor de los derechos del ciudadano, en voz del pueblo; que pueda, por ejemplo, denunciar la subida de los precios, o exigir que los enfermos estén bien asistidos (Obras IV:179). Asimismo, la labor del periodista ha de tener como fin primordial la educación pública, pues tal como señala en el prospecto de su último periódico, el Correo Semanario de México, los periódicos tienen la función primordial de ser útiles a las naciones civilizadas, "pues por su medio y a poca costa se derrama la ilustración por todas partes" (Obras VI:5).

Fernández de Lizardi considera que el periodista debe ser ante todo sincero con sus lectores y con sus colegas periodistas, honesto a la hora de citar en sus trabajos a otros autores - por eso se molesta tanto cuando se le tacha de plagiarioEsta honestidad a la hora de escribir ha de partir desde la firma de los artículos. El Pensador critica a aquellos que se enfundan en apodos para lanzar sus puyas a resguardo. Veamos cómo increpa a un papelista por su falta de valentía a la hora de publicar infamias contra él en su folleto "Barbero rapa barbero"

Si quiere escribir más contra mí, no sea miedoso, fírmese como yo, y el día que vea un papel firmado con su nombre y apellido, le dejaré en la imprenta dos pesillos para que [se] refresque a mi nombre; pero si no se firma, haré lo que los mastines cuando les ladra un escuintle [perrillo], que lo ven, lo mean y no le hacen caso (Obras XII:98).

La sinceridad y la necesidad de expresarse siempre en libertad acarrearon al Pensador no pocos problemas: encarcelamientos, excomunión, múltiples censuras y un sinfín de rencillas con otros escritores. Sus enemigos se lanzaron ferozmente contra él en los momentos más difíciles de su vida; fue llamado "firmón, paparruchero, depositario de las furias del infierno, maromero, majadero, capitancillo, capitán de caridad, capitán araña, chaqueta, animal, caballo", 8 entre otros calificativos. La admiración que despertaba en sus seguidores y las polémicas que se gestaban en torno a su figura provocaron, además, que el hablar de Lizardi se

\footnotetext{
${ }^{8}$ Con estos improperios lo llamó José María Aza en su papel "Cayó el pobre Pensador del partido liberal”. Referido por Palazón en su Introducción a Fernández de Lizardi (Obras VI:21).
} 


\section{Mariela Insúa}

transformara en un negocio rentable. ${ }^{9}$ En varios de sus folletos, el Pensador se defiende contra aquellos que lo atacan despiadadamente, e indica que todo escritor público ha de velar por la verdad, pero siempre respetando a quien es objeto de crítica. Así le contesta a un tal Guapo que se ha burlado de su excomunión

¿Ya ve usted cómo no lo llamo vil, ni pícaro, ni hereje, ni cojo, tuerto [Lizardi era bizco], manco ni cosa que lo deshonre? Es menester que usted, el Boticario y todos mis rivales aprendan que la crítica es el arte de buscar la verdad, no el de manifestarnos groseros, insultando a quien no podemos convencer. Escriban vuestras mercedes cuanto quieran; pero con juicio y urbanidad: de otro modo dan a entender que les falta la razón y echan mano del sarcasmo, la injuria y la chocarrería. ¡Qué pequeñez! (Obras XII:155).

En otro folleto de 1822, titulado "El Pensador, llama a juicio a sus necios enemigos", Lizardi critica a sus detractores por carecer de razones sólidas y recurrir al sarcasmo y a los improperios a la hora de valorarlo como escritor. Esto no quita que él mismo se lance con furibunda gracia contra ellos, y haga sátira de sus estilos. Así, por ejemplo, se refiere a la escritura apocada del conocido como Esmeregildo

Oye, maldito bachiller, que ni escribir sabes: ¿quién te ha metido a guapo ni a faceto, cuando tus obras manifiestan que te engendraron al pie de un volcán de nieve y te parieron en lo más helado del invierno? Ni lógica, ni criterio, ni estilo, ni erudición, ni doctrina, ni gracia, ni principios de educación ni nada bueno manifiestas en tus infelices mamarrachos. Pero, ¡qué más!, si ni escribir sabes (Obras XII:172).

En suma, el Pensador supo defenderse y defender la actividad de escritor que respetaba y desempeñaba juiciosamente. Para el Lizardi ilustrado, el escritor debía comportarse siempre como un "amante del bien común" y tener como principal tarea el proponer medios para la felicidad general (Obras III:346), en el sentido que el siglo XVIII le otorgó al término felicidad; es decir, como la consecución del bienestar en el mundo a nivel individual y colectivo (Álvarez Barrientos, 1990:104).

Las ideas políticas y sociales reflejadas en los trabajos de prensa de nuestro autor ponen de manifiesto los dos principales objetivos éticos de su producción y de su vida: demostrar a los habitantes de la Nueva España, y luego a los ciudadanos de la patria mexicana, que era posible, con educación y trabajo, conseguir esa añorada sociedad feliz, y, en segundo término, denunciar las ambigüedades y egoísmos que lo estaban impidiendo. ${ }^{10}$ Recordemos en relación

\footnotetext{
${ }^{9}$ Las hojas volantes escritas en contra del Pensador fueron editadas principalmente por Juan Cabrera y publicadas en la Oficina de Alejandro Valdés. Ver, Introducción de Palazón a Fernández de Lizardi (Obras VI:20-21).

${ }^{10}$ Este tema lo he desarrollado más en detalle en Insúa (2009), especialmente en el capítulo II, dedicado al modelo de vida del hombre de letras y en Insúa (2010).
} 
con esto que Fernández de Lizardi fue ante todo un educador nato y, que tanto su periodismo como su producción en general, responden a la premisa pedagógica de instruir al pueblo con miras a conseguir la armonía social. Por ello, según él mismo explica, este "médico del público" muchas veces, al velar por la salud de la patria, debe administrar bebidas saludables a sus habitantes, aunque sepan amargas y resulten ingratas al paladar (Obras III:383).

En resumidas cuentas, Lizardi retrata en su obra periodística a un escritor de nuevo cuño - moderno en las formas, pero tan virtuoso como los sabios admirados desde antiguo- que, junto a otros agentes sociales como los educadores, los trabajadores y las mujeres, ${ }^{11}$ está llamado a abonar la tierra para que germinen ciudadanos ejemplares capaces de forjar la nueva nación independiente.

Universidad de Navarra* Grupo de Investigación Siglo de Oro (GRISO)

Campus universitario $s / n$ 31009 Pamplona-Navarra (España) minsua@unav.es

\section{BIBLIOGRAFÍA}

Álvarez Barrientos, Joaquín. Ilustración y Neoclasicismo en las letras españolas. Madrid: Síntesis, 2005.

------- "Cuando las letras llegaron a ser "de cambio": sobre la República literaria española en el siglo XVIII". De misticos y mágicos, clásicos y románticos. Ed. A. Calderone. Messina: Armando Siciliano, 1993:33-46.

------ "El periodista en la España del siglo XVIII y la profesionalización del escritor", en Estudios de Historia Social 52-53. 1990:29-39.

Fernández de Lizardi, José Joaquín. El Periquillo Sarniento. Ed. Carmen Ruiz Barrionuevo. Madrid: Cátedra, 1997.

------ Obras XII. Folletos (1822-1824). Ed. Irma Fernández y María Rosa Palazón, México: Universidad Nacional Autónoma de México, 1995.

Obras XI. Folletos (1821-1822). Ed. Irma Fernández. México: Universidad Nacional Autónoma de México, 1991.

------ Obras VI. Periódicos. Correo Semanario de México. Ed. María Rosa Palazón. México: Universidad Nacional Autónoma de México, 1975.

------ Obras V. Periódicos. El Amigo de la Paz y de la Patria, El Payaso de los Periódicos, El Hermano del Perico que cantaba la Victoria, Conversaciones del Payo y el Sacristán. Ed. María Rosa Palazón. México: Universidad Nacional Autónoma de México, 1973.

Obras IV. Periódicos. Alacena de Frioleras, Cajoncitos de la Alacena, Las Sombras de Heráclito y Demócrito, El Conductor Eléctrico. Ed. María Rosa Palazón. México: Universidad Nacional Autónoma de México, 1970.

\footnotetext{
${ }^{11}$ En Insúa (2009) se aborda por extenso el papel de estos modelos de vida en la obra de Lizardi.
} 
Obras III. Periódicos. El Pensador Mexicano. Ed. María Rosa Palazón y Jacobo Chencinsky. México: Universidad Nacional Autónoma de México, 1968.

------ Obras I. Poesía y fábulas. Ed. Jacobo Chencinsky y Luis Schneider. México: Universidad Nacional Autónoma de México, 1963.

Franco, Jean. "La heterogeneidad peligrosa: escritura y control social en vísperas de la independencia mexicana". Hispamérica 34-35. 1983:3-34.

Insúa, Mariela. "Periodismo y sociedad en la Nueva España de la Ilustración: José Joaquín Fernández de Lizardi”. Textos sin fronteras. Estudios sobre Literatura y sociedad. Ed. Tapsir Ba, Álvaro Baráibar, Ruth Fine y Carlos Mata. Pamplona: Eunsa, 2010:151-163.

------ Modelos de vida en la Nueva España de la Ilustración: José Joaquín Fernández de Lizardi, tesis doctoral inédita. Pamplona: Universidad de Navarra, 2009.

Oviedo y Pérez de Tudela, Rocío. La obra de Joaquín Fernández de Lizardi. Prosa periodística, tesis doctoral inédita. Madrid: Universidad Complutense, 1982. 